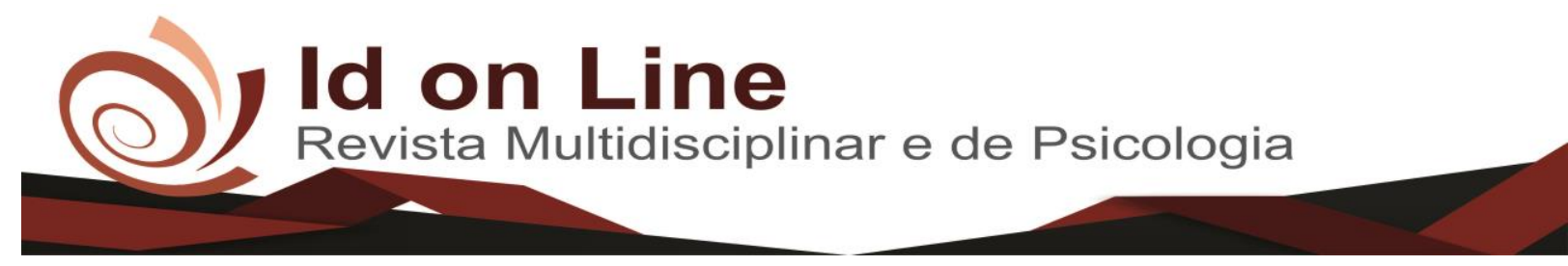

Artigo

\title{
A Mulher e sua Atuação no âmbito da Logística: Um estudo de casos múltiplos na Região do Cariri
}

\author{
Maria Taina Araujo Silva Borges ${ }^{1}$ Alyne Leite de Oliveira ${ }^{2}$
}

\begin{abstract}
Resumo: Em um cenário onde a mulher tem cada vez mais espaço no mercado de trabalho, ainda se percebe algumas restrições quanto à sua atuação em algumas áreas. No âmbito da logística, campo vasto em atuação e de grande importância não apenas nas organizações, mas no direcionamento das atividades diárias das pessoas, se fez importante compreender os desafios enfrentados pela mulher frente a atual conjuntura e exigências no tocante à inserção e manutenção da profissão. A pesquisa em questão traz em seu cerne além de um contexto de empoderamento feminino, uma discussão que perpassa os desafios da inserção da mulher no mercado de trabalho, adentrando o principal enfoque da gestão, que visa resultados efetivos, sendo esse estudo no âmbito da logística. Foram selecionadas por acessibilidade e julgamento do pesquisador, 04 mulheres que atuam na área de logística na cidade de Juazeiro do Norte-CE, há pelo menos 02 anos, formadas na área ou afins, entre 29 e 35 anos. Foi utilizado como instrumento de coleta de dados, um roteiro de entrevista estruturado, gravado com uso de um celular. Os resultados apontam que as profissionais entrevistadas estão na direção evolutiva no contexto de empoderamento feminino, demonstrando que estão não apenas aptas a atuarem no ramo da logística, mas principalmente, tem competência para tal. E na contramão dos preconceitos, ainda vigentes, se destacam em suas atuações, podendo perceber, inclusive, reconhecimentos advindos de seu trabalho e dispostas a galgar uma carreira de sucesso.
\end{abstract}

Palavras-Chave: Logística. Mercado de Trabalho. Empoderamento Feminino.

\section{The Woman and her Performance in Logistics: Multiple Case studies in the Cariri Region}

\begin{abstract}
In a scenario where women have more and more space in the labor market, there are still some restrictions on their performance in some areas. In the field of logistics, a vast field in action and of great importance not only in organizations, but in directing the daily activities of people, it became important to understand the challenges faced by women in the current situation and requirements regarding the insertion and maintenance of the profession. The research in question brings in its core beyond a context of female empowerment, a discussion that crosses the challenges of the insertion of women in the labor market, entering the main focus of management, which aims at effective results, being this study in the field of logistics . Fourteen women who worked in the area of logistics in the city of Juazeiro do Norte-CE, for at least 2 years, trained in the area or related, between 29 and 35 years old were selected for accessibility and judgment of the researcher. A structured interview script, recorded with the use of a cell phone, was used as a data collection instrument. The results indicate that the professionals interviewed are in the evolutionary direction in the context of female empowerment, demonstrating that they are not only able to act in the logistics sector, but mainly, it has the competence to do so. And against the preconceptions, still in force, they stand out in their performances, being able to perceive, inclusively, recognitions coming from their work and arranged to achieve a career of success.
\end{abstract}

Keywords: Logistics. Job market. Female Empowerment.

\footnotetext{
${ }^{1}$ Graduanda em Administração no Centro Universitário Doutor Leão Sampaio/UNILEÃO-Juazeiro do Norte, Ceará-Brasil. Contato: mariataina26@gmail.com

${ }^{2}$ Professora Orientadora do Centro Universitário Doutor Leão Sampaio/UNILEÃO, Juazeiro do Norte, Ceará- especialista em logística empresarial. Contato: alyneoliveira@leaosampaio.edu.br
} 


\section{Introdução}

Em uma época de avanço tecnológico, alto índice de automação, profissões precisando se redesenhar para se manter atuantes, e as mulheres se destacando de forma significativa nesse contexto, ainda se percebe a existência de paradigmas para atuação das mesmas, especialmente em algumas profissões.

Este trabalho tem por objetivo compreender os desafios enfrentados pela mulher frente a atual conjuntura e exigências no tocante à inserção e manutenção da profissão. A pesquisa em questão traz em seu cerne além de um contexto de empoderamento feminino, uma discussão que perpassa os desafios da inserção da mulher no mercado de trabalho, adentrando o principal enfoque da gestão, que visa resultados efetivos, sendo esse estudo no âmbito da logística.

Para a busca de resultados, o estudo se desenhou a partir de uma pesquisa descritiva, com abordagem qualitativa, a partir de casos múltiplos com 04 mulheres profissionais com atuação na área em estudo, e análise de dados com base na análise de conteúdo (AC).

O trabalho estruturou-se inicialmente com uma abordagem acerca da área de logística, adentrando conceitos, características do profissional e da área de atuação, logo após trouxe uma breve discussão acerca da evolução da mulher no mercado de trabalho e por fim, o método e análise dos principais resultados coletados em campo.

\section{Logística: Conceito, Atividades, Carreira}

O termo "logística", embora muito utilizado nos dias atuais, só teve destaque após a segunda guerra mundial, dada a necessidade do planejamento estratégico e da alocação devida de suprimentos alimentícios, bélicos e de pessoas. Só após esse período, o termo teve destaque nas organizações, por representar o planejamento das atividades agregando valor de lugar, tempo e informação aos processos (BALLOU, 2007; NOVAES, 2004; BOWERSOX et al., 2014).

Durante muitas décadas o processo era tido apenas como atividade operacional, não dando ao mesmo o glamour devido ao valor por ele agregado. O mesmo esteve por vezes associado às áreas de finanças, marketing ou produção (BALLOU, 2007). Só após a década de 90, fase esta denominada por Novaes (2004) de integração estratégica, surge a percepção da necessidade da integração dos membros aos quais o processo logístico estava inserido. Surge 
então a necessidade do gerenciamento da cadeia de suprimentos (Supply Chain Mannagement/SCM).

Para gerenciamento da cadeia de suprimentos se faz necessária a compreensão da existência das atividades primárias e de apoio que compõem o processo logístico. Portal Educação (2018) cita três atividades ditas principais ou primárias, sendo Transportes, manutenção de estoques e processamento de pedidos. Ballou (2007) destaca que estas são assim denominadas por demandarem cerca de 60 a $70 \%$ dos custos operacionais da empresa. Delas advém as atividades de apoio, pois dão suporte ao desempenho das demais, sendo armazenagem, manuseio de materiais, embalagem de proteção, obtenção, programação do produto, manutenção da informação (PORTAL EDUCAÇÃO, 2018).

O processo logístico vai muito além do simples transporte ou armazenagem de materiais. Sales (2007. p.49) destaca que o profissional que atua nessa área requer "profundo conhecimento técnico aplicado à prática, sólida base teórica, visão abrangente do negócio, foco no cliente, capacidade de negociação, experiência na área comercial, habilidade para liderar e motivar pessoas, noções financeiras" e, ainda destaca a necessidade de um inglês fluente, de maneira que "permita discutir contratos com qualquer parte do mundo".

Percebe-se, desse modo, que a logística se estrutura a partir dos processos inbound, planta (intralogística) e outbound, necessitando conhecer, planejar e operar desde os modais de transporte (rodoviário, ferroviário, aeroviário, aquaviário e dutoviário) existentes (BALLOU, 2007) e disponíveis e viáveis à cada região ou carga, inclusive aderindo à inovações com o uso de drones (LIMA JUNIOR, 2017), até a escolha, planejamento e execução do melhor equipamento de movimentação (empilhadeiras, paleteiras, transelevadores, bondinhos, eletromonovias, esteiras...) e armazenagem (paletes, estanterias, estruturas porta paletes, armazéns refrigerados, contêineres...) (BALLOU, 2007) devido à operação vigente.

É atribuição do profissional da área tomar decisões de curto, médio e longo prazos, a partir do âmbito da sua atuação, nos níveis operacional, tático ou estratégico. Suas decisões perpassam desde a carga a ser carregada e roteirizada, à melhor rota a ser seguida ou à aquisição de frota própria ou terceirizada; à decisão dos níveis de estoque a serem mantidos à partir de previsões de demandas, planejamento das necessidades de material (Material requerimento program/MPR), decisões de compra associadas à manufatura (Manufacturing resource planing/MRP II) e o planejamento integrado da empresa (Enterprise resource planing/ERP) (POZO, 2015).

Por ser considerada um processo de planejamento, implementação e controle de fluxos, a logística visa a acurácia das informações associadas aos processos citados anteriormente, e 
muitas vezes, incluindo os fluxos reversos ao longo da cadeia de suprimentos (BALLOU, 2007). Isso garante à empresa não apenas a satisfação do cliente, mas a manutenção da mesma em meio à competitividade acirrada.

Embora a profissão tenha em sua essência uma gama de atividades comumente exercidas por homens, por exigirem trabalho braçal. Esta não se limita a esse quesito, pois por outro lado e até mesmo no contexto estratégico em que se insere, exige planejamentos detalhados e minunciosos que competem perfeitamente à expertise feminina.

\section{A Evolução da Mulher no Mercado de Trabalho e seu Desempenho na Logística}

Durante muito tempo o papel da mulher se restringiu à atividades domésticas, cuidado com os filhos e com o cônjuge, delegando ao homem o papel de provedor das necessidades do lar (PROBST, 2015). Mendonça (2017) cita que devido a inserção dos homens nos campos de guerra, o tempo dado às ausências dos seus companheiros, muitas ficaram sem seus maridos, e assim tinha que buscar um meio de prover o próprio sustendo e dos seus filhos, momento este em que começaram a atuar fora do lar, sendo muitas vezes desvalorizadas (MENDONÇA, 2017).

Brasil (2018) destaca que "as mulheres só passaram a dispor de direitos políticos no País a partir de 1932, quando conquistaram o direito de votar e de serem eleitas”. E embora a mulher venha se inserido no mercado de trabalho, na política e em áreas diversas, o termo e o próprio empoderamento só começou a ter destaque no início do sec. XXI, devido a movimentos sociais de fortalecimento dos direitos da mulher.

São várias as conquistas femininas ao longo dos anos, ainda que, com muitas lutas, foram instituídas leis contra violência doméstica, violência de gênero, assédio moral e sexual (BRASIL, 2018). Por outro lado, no quesito trabalho, "segundo dados do Instituto Brasileiro de Geografia e Estatística (IBGE), no Brasil as mulheres trabalham em média até três horas a mais do que os homens, além de dedicarem mais tempo do que eles aos afazeres domésticos". E ainda destaca que, ainda que sua jornada seja mais ampla, "as mulheres recebem $76,5 \%$ do salário pagos aos homens na mesma função" (BRASIL, 2018).

Porém, "foi-se o tempo em que as profissões eram exclusivamente masculinas ou femininas. Hoje, com a crescente inserção da mulher no mercado de trabalho, elas estão buscando espaço e igualdade nos mais variados segmentos. Na logística, não é diferente" (REVISTA MUNDO LOGÍSTICA, 2018, s/p). Embora a mulher venha ganhando espaço nesse 
universo, até pouco tempo se acreditava que um mercado que "envolvia movimentação de cargas, porto e logística era tipicamente masculino" (REVISTA MUNDO LOGÍSTICA, 2018, $\mathrm{s} / \mathrm{p})$.

O caminho profissional da mulher vem trazendo destaque para cargos que eram somente masculinos, atuando hoje na gestão e operacionalização de atividades industriais nas mais diferentes partes do mercado, tendo alcançado uma ampliação expressiva da força feminina em vários lugares (RODRIGUES, 2017).

No que se refere à manutenção da profissão, percebe-se que esse é um período em que buscam soluções eficientes para a cadeia logística, havendo uma forte tendência que esses profissionais sigam se valorizando no futuro, conforme dados de Gauchazh (2018), principalmente por que o Brasil tem uma infraestrutura logística deficitária, necessitando de investimentos para enfrentar o gargalo em questão, ampliando o leque de atuação da mulher, que pode ser desde o contexto operacional à atividades de gestão, desde o redesenho dos processos logísticos à atividades voltadas ao comercio exterior..

Outro desafio enfrentado pela mulher se refere às jornadas duplas, pela necessidade de administrar a rotina pessoal e a vida corporativa. Kumruiam (2018 apud MULHERES POSITIVAS, 2018) destaca que se faz necessário o apoio e suporte do companheiro para conseguir equilibrar a rotina e enfatiza que mulheres, mães, executivas, aprendem muito rápido que tudo na vida são escolhas e, visto que não há possibilidade de se estar em dois lugares ao mesmo tempo, é necessário contar com muita disciplina com horários e compromissos, fazendo de cada situação a mais produtiva possível.

Campos (2018) destaca características consideradas femininas fundamentais para o sucesso profissional, tais como: "inteligência emocional, empatia para engajar a equipe, atenção aos detalhes, foco e preocupação com pessoas e maleabilidade".

Para um ótimo desenvolvimento na empresa é bom ressaltar que o fator que vai diferenciar entre o homem e mulher é competência, pois todos tem a capacidade de manusear equipamentos e até mesmo liderar grupos, entre vários níveis e é isso que vai caracterizar a carreia bem sucedida de cada um profissional, portanto há diversas processos e agilidades que exigem da sensibilidade, de um olhar mais minucioso, do pensamento global, para conseguir resultados mais objetivos e efetivos (RODRIGUES, 2017). 


\section{Método}

A proposta investigativa aqui apresentada caracteriza-se como de natureza básica, objetivo descritivo, abordagem qualitativa, cujo procedimento desenhou-se a partir de um estudo de casos múltiplos.

A pesquisa descritiva é uma pesquisa que proporciona uma descrição de um público, a partir de um acontecimento ou um fato, é basicamente um estudo observado pelas modificações das variáveis do objeto, relacionadas em volume, medida que possa ser analisado diante do processo alcançado (DUARTE, 2012).

Yin (2001, p. 75) menciona que "qualquer utilização de projetos de casos múltiplos deve seguir uma lógica de replicação, e não de amostragem, e o pesquisador deve escolher cada caso cuidadosamente".

Foram selecionadas por acessibilidade e julgamento do pesquisador, mulheres que atuam ou atuaram na área em estudo há pelo menos 02 anos, formadas na área ou afins, com faixa etária entre 29 e 35 anos e que tivessem disponibilidade para responder aos questionamentos necessários à busca de resultados, chegando-se à seleção de 04 mulheres que se enquadravam no perfil desejado para análise.

Como instrumento para a coleta de dados foi utilizado um roteiro de entrevista estruturado, gravado com uso de um celular. A entrevista estruturada é alcançada com base em um plano com perguntas exclusivas, cujo principal benefício é a uniformização (MARQUES, 2018).

Os dados coletados foram analisados por meio da análise do conteúdo, que "pode ser definida como um conjunto de instrumentos metodológicos, em constante aperfeiçoamento, que se presta a analisar diferentes fontes de conteúdos (verbais ou não-verbais)", cuja interpretação "transita entre dois polos: o rigor da objetividade e a fecundidade da subjetividade". (FREITAS, CUNHA E MOSCAROLA apud SILVA e FOSSÁ, 2013). Os autores ainda mencionam que deve ser operacionalizada seguindo as seguintes etapas: pré-análise, exploração do material e tratamento dos resultados, inferência e interpretação (BARDIN, 2006 apud SILVA e FOSSÁ, 2013). 


\section{Análise e discussão dos resultados}

Tendo em vista o objetivo proposto por esse estudo, a partir das entrevistas realizadas, observou-se a incidência de palavras a partir dos conteúdos dos discursos das participantes, e foram analisadas as seguintes categorias: Trajetória, Desafios, Empoderamento feminino, Desempenho na área, Perfil Profissional e Carreira em Logística.

No tocante ao perfil das pessoas entrevistadas, destaca-se a adesão ao público feminino, visto ser o foco do trabalho, com faixa etária entre 29 e 35 anos, todas atuando na área de gestão, seja com atuação direta na área objeto do trabalho, área afim ou que tenha tido alguma ligação com a mesma, porém com formação na área de logística. As entrevistadas começaram sua vida profissional como auxiliar e assim foram se especializando onde tiveram avanços em seus cargos.

Quadro 1: Perfil das Participantes

\begin{tabular}{|l|c|l|c|}
\hline \multicolumn{1}{|c|}{ Participantes do Estudo } & Idade & \multicolumn{1}{|c|}{ Área de Formação } & $\begin{array}{c}\text { Tempo de atuação } \\
\text { na área }\end{array}$ \\
\hline Entrevistada 1 & 29 & Administração/pós em logística & 1 ano \\
\hline Entrevistada 2 & 31 & $\begin{array}{l}\text { Engenharia de produção mecânica /pós em } \\
\text { logística }\end{array}$ & 8 anos \\
\hline Entrevistada 3 & 34 & $\begin{array}{l}\text { Engenharia de produção mecânica/pós em } \\
\text { logística }\end{array}$ & 11 anos \\
\hline Entrevistada 4 & 35 & Contabilidade/pós em logística & 16 anos \\
\hline
\end{tabular}

Fonte: Dados da Pesquisa (2018).

Visto que se pretendia discutir acerca da história profissional na área, se fez relevante compreender a trajetória seguida pelas mesmas, adentrando a categoria supracitada.

Quadro 2: Categoria "Trajetória"

\begin{tabular}{|c|c|}
\hline Participantes & Relatos \\
\hline E1 & $\begin{array}{l}\text { Quando eu terminei a faculdade, eu terminei no ano de... eu comecei no ano de } 2012 \text { terminei } \\
\text { no ano de } 2016 \text {, tá com dois anos que eu terminei. É a princípio eu não trabalhava na área, eu } \\
\text { era assistente administrativo numa floricultura aqui na cidade mesmo, porem assim que eu } \\
\text { terminei, eu recebi o meu diploma... É eu já corri atrás fui pro mercado de trabalho até por } \\
\text { que eu não queria sair da cidade e a xxx, a indústria estava começando a migrar as empresas } \\
\text { pra cá, que foi a www e xxx está fazendo a sola. Daí foi por indicação uma amiga minha pediu } \\
\text { meu currículo e eu fui selecionada para a entrevista, dessa entrevista eu fui recrutada para } \\
\text { fazer parte do RH, só que a empresa era pequena e eu tinha que adquirir uma experiência para } \\
\text { poder começar eu não tinha essa experiência no RH, então os gestores viram que eu poderia } \\
\text { ir para outra parte, e vim fazer essa parte de PCP, que e controle de programação e } \\
\text { controle de produção onde a gente inicia e termina aqui no PCP, já faz } 1 \text { ano de empresa } \\
\text { depois que eu terminei a faculdade logo em seguida entrei aqui nessa empresa. . }\end{array}$ \\
\hline E2 & $\begin{array}{l}\text { Eu entrei na área da logística Faculdade de Engenharia de Produção estava cursando o oitavo } \\
\text { período ai surgiu uma vaga de estágio na xxx na área de logística, comecei como estagiária } \\
\text { depois de um ano fui contratada na área de logística, PCP logística. }\end{array}$ \\
\hline
\end{tabular}




\begin{tabular}{|l|l|}
\hline E3 & $\begin{array}{l}\text { Pronto, minha trajetória.. É sou formada em engenharia de produção fiz MBA em logística } \\
\text { formei em } 2009 \text { e uma das maiores experiência que tive foi lá na bom sinal, quando eu } \\
\text { trabalho até hoje desde } 2011 \text { no setor de planejamento sempre dando suporte na área de } \\
\text { suprimentos. }\end{array}$ \\
\hline E4 & $\begin{array}{l}\text { Eu tenho a minha idade é } 35 \text { anos, eu comecei com logística já com } 16 \text { anos interrompi a um } \\
\text { ano e meio para poder montar meu escritório contabilidade, Comecei de um cargo pequeno } \\
\text { como auxiliar de caixa eu já me identifiquei e quem trabalha com logística adora uma coisa } \\
\text { difícil para resolver né, Aí fui crescendo em seguida passei ser assistente de caixa a ser gerente } \\
\text { caixa e me tornei Gerente de Logística posteriormente monitora de logística e auditora } \\
\text { de logística ou seja eu tenho um conhecimento um leque enorme operacional, } \\
\text { administrativo, rotas que vem os carros caminhóes, que vem a mecânica que vem também } \\
\text { a parte fiscal os postos ficais do decreto não decreto, impostos e não impostos que o cliente } \\
\text { nuca entende que pra receber a mercadoria é necessário que faça a efetivação do DAI posterior } \\
\text { a isso pedi demissão. A empresa inclusive, foi ai que montei minha transportadora, foi ai } \\
\text { que me apaixonei mais ainda por que aquilo que se traz outra perspectiva de conhecimento } \\
\text { seus olhos abrem mais uma outra ótica buscar mais conhecimento. Foram 16 anos. }\end{array}$ \\
\hline
\end{tabular}

Fonte: Dados da Pesquisa (2018).

Percebe-se, frente à trajetória descrita pelas participantes do estudo, a incidência de palavras que refletem as atividades que permeiam a profissão, tais como: PCP, planejamento, suprimentos, auditoria, rotas, transportadora, dentre outras. É importante destacar que, conforme cita Portal Educação (2018) e Ballou (2007) essas são atividades primárias e de apoio ao processo logístico, que se bem gerenciadas agregarão valor de tempo, lugar, qualidade e informação à cadeia logística e seu controle propiciará a minimização dos custos associados à todo o processo, garantido assim a satisfação de todos os envolvidos no mesmo.

Quadro 3: Categoria "Desafios"

\begin{tabular}{|c|c|c|c|}
\hline Participantes & Dificuldades & Exigências & Desigualdade \\
\hline Entrevistada 1 & $\begin{array}{l}\text { Há inúmeras hoje a gente } \\
\text { trabalha aqui o ambiente é } 95 \% \\
\text { masculino. Na administração } \\
\text { em si somos só três meninas aqui } \\
\text { e assim não que eu veja uma } \\
\text { questão de dificuldade por parte } \\
\text { delas mas é mais pela aceitação } \\
\text { também a questão que ainda } \\
\text { há preconceito, mas já melhor, } \\
\text { melhorou muito mas ainda há } \\
\text { preconceito em relação a isso. }\end{array}$ & $\begin{array}{l}\text { Sim, esse perfil sim, por } \\
\text { que a mulher já entra } \\
\text { nesse tipo de emprego } \\
\text { desacreditada, já como } \\
\text { incapaz e a gente tem } \\
\text { provar além disso ser } \\
\text { uma profissional tem } \\
\text { provar que você é } \\
\text { capaz então eu acho que } \\
\text { já entra desacreditada e } \\
\text { em outras questões } \\
\text { salários menores. }\end{array}$ & $\begin{array}{l}\text { Eu acho que a visão em geral } \\
\text { a visão de igualdade mesmo, } \\
\text { em uma certa parte dos } \\
\text { gestores que estão acima né e } \\
\text { também há a visão é no } \\
\text { geral machista que ainda há } \\
\text { não que a gente tem que } \\
\text { mudar em qualquer tipo de } \\
\text { área que esteja atuando. }\end{array}$ \\
\hline Entrevistada 2 & $\begin{array}{l}\text { Por conta de eu ser mulher não } \\
\text { vejo nenhuma questão de } \\
\text { problema é tanto que lá na xxx } \\
\text { eu sou responsável na parte do } \\
\text { planejamento } \\
\text { reabastecimento peças da } \\
\text { fábrica da planta daqui de } \\
\text { Juazeiro, são três mulheres, tem } \\
\text { e nenhum homem nessa parte e } \\
\text { foi saindo ai temos três } \\
\text { programadoras aqui no juazeiro }\end{array}$ & $\begin{array}{l}\text { Também não vejo } \\
\text { diferença nenhuma, só } \\
\text { que a maioria dos meus } \\
\text { fornecedores a maioria é } \\
\text { homem, conta no dedo as } \\
\text { mulheres, têm... Mas são } \\
\text { poucas. }\end{array}$ & $\begin{array}{l}\text { Tem ainda, por que a maioria } \\
\text { é homem né, mas eu acho q } \\
\text { assim nenhum homem } \\
\text { impede a mulher de ir pra } \\
\text { área que ela quiser não, } \\
\text { depende da mulher seguir a } \\
\text { carreira que ela quer ir }\end{array}$ \\
\hline
\end{tabular}




\begin{tabular}{|c|c|c|c|}
\hline & $\begin{array}{l}\text { e uma lá em são Paulo, assim por } \\
\text { eu ser mulher e nem umas três } \\
\text { não ver nenhum problema. }\end{array}$ & & \\
\hline Entrevistada 3 & $\begin{array}{l}\text { Eu vejo assim a principal } \\
\text { dificuldade nessa área pelo } \\
\text { menos onde eu trabalho, pois eu } \\
\text { trabalho com trem, para os } \\
\text { homens absorverem isso, que } \\
\text { uma mulher né, está no meio } \\
\text { dessa área entre aspas, } \\
\text { mandando, foi difícil para eles } \\
\text { entenderem isso e absorverem. }\end{array}$ & $\begin{array}{l}\text { Eu creio que sim, é como } \\
\text { se muitas vezes o } \\
\text { mercado de trabalho } \\
\text { lhe testasse pelo menos } \\
\text { comigo e aconteceu isso, } \\
\text { nas três empresas que eu } \\
\text { trabalhei tanto na xxx } \\
\text { por um tempo fábrica de } \\
\text { calçados né, na área de } \\
\text { PCP e a gente acaba aqui } \\
\text { tendo contato diário com } \\
\text { chão de fábrica. }\end{array}$ & $\begin{array}{l}\text { Eu vejo que muitas vagas } \\
\text { de empregos que são } \\
\text { ofertadas né, elas acaba } \\
\text { distinguindo dizendo ne o } \\
\text { sexo masculino e sexo } \\
\text { feminino eu acho que as } \\
\text { empresas devia avaliar os } \\
\text { candidatos com entrevista e } \\
\text { tudo para depois escolher se } \\
\text { é homem ou mulher, por que } \\
\text { a mulher não né. Eu } \\
\text { trabalho em uma } \\
\text { montadora de trem e } \\
\text { ninguém acredita e quem } \\
\text { faz todo planejamento sou } \\
\text { eu, e hoje isso é muito bem } \\
\text { aceito pois é desde } 2011 \text { a } \\
\text { oito anos já }\end{array}$ \\
\hline Entrevistada 4 & $\begin{array}{l}\text { A mulher não tem dificuldade, o } \\
\text { que é preciso é que a mulher ela } \\
\text { se prepare, por que quando se } \\
\text { pretende trabalhar em um local } \\
\text { assumir um cargo mais alto, } \\
\text { consequentemente uma } \\
\text { remuneração, a sua competência } \\
\text { é preciso que a mulher estude } \\
\text { que a mulher busque } \\
\text { conhecimento então não há } \\
\text { dificuldade, há dificuldade pro } \\
\text { empresariado pessoas ter } \\
\text { preparadas. }\end{array}$ & $\begin{array}{l}\text { Não, ele é abrangente, } \\
\text { por que se o mercado } \\
\text { trabalha pra quem é } \\
\text { capacitado e quem é } \\
\text { competente, se você é } \\
\text { competente então é } \\
\text { indefinido o seu gênero } \\
\text { no mercado de } \\
\text { trabalho. }\end{array}$ & $\begin{array}{l}\text { É exatamente isso não tem } \\
\text { desigualdades, a ação que } \\
\text { pode tomar independente } \\
\text { da mulher e do homem } \\
\text { passa a estudar e ter } \\
\text { conhecimento. }\end{array}$ \\
\hline
\end{tabular}

Fonte: Dados da Pesquisa (2018).

No tocante aos desafios percebidos para a inserção no mercado de trabalho, bem como para atuação na área, observa-se a incidência dos termos " ambiente masculino, preconceito, aceitação, machismo, teste", entre outros, caracterizando que as profissionais, embora com qualificação para atuação na área e até mesmo em cargos de liderança, ainda percebem descrédito na execução de suas atividades, o que requer tempo para então ser dado o devido valor, fato este observado na fala da entrevistada 2, que destaca que é responsável por todo o planejamento e não percebe diferença no tratamento do seu trabalho. Esses aspectos são destacados por Probst (2015) e Revista Mundo Logística (2018) ao citarem a evolução da mulher a partir de atividades meramente domésticas para inserção e bom desempenho de atividades vistas anteriormente executadas apenas por homens. 
Quadro 4: Categoria "Empoderamento feminino"

\begin{tabular}{|l|l|}
\hline Participantes & Dupla Jornada \\
\hline Entrevistada 1 & $\begin{array}{l}\text { Bom, minha rotina é bem agitada, como eu disse no início o processo começa e termina } \\
\text { aqui onde a gente recebe os pedidos do setor de compras e vendas né, ai aqui a gente começa } \\
\text { a processa-los a partir de digitação de pedido, colocar é fazer a programação matéria prima } \\
\text { onde essa matéria prima vai ser processada e ela possa ser disponibilizada para a produção } \\
\text { onde a produção vai processa-las no nosso caso aqui é o setor de vulcanização onde a sola vai } \\
\text { ser prensada e vai sair nesse formato e depois vai expedição e da expedição para o cliente } \\
\text { então a gente programa as datas a que vão ser quando a datas vão receber, aqui a gente está } \\
\text { para resolver problemas. }\end{array}$ \\
\hline Entrevistada 2 & $\begin{array}{l}\text { Parece que é mais cansativo, porque quando eu chego em casa aqui vou ter que fazer } \\
\text { tudo, comida, cuidar de casa e cuidar menino que é o mais cansativo. Acho que por isso que } \\
\text { eu estou de férias, mas eu estou assim já vou ter que voltar pra descansar, mas assim é } \\
\text { cansativo demais, mas compensa eu não eu não trocaria minha vida de casada com filho } \\
\text { e trabalhando fora, para ser dona de casa, tenho certeza que não. }\end{array}$ \\
\hline Entrevistada 3 3 & $\begin{array}{l}\text { Minha rotina quinta e sexta faço mais no planejamento e segunda terça e quarta faço } \\
\text { acompanhamento em lote, reunião a suprimento em relação a compra e vendas, nós temos } \\
\text { uma produção de dois carros "trem" por mês, e eu tenho que fazer a programação toda semana. }\end{array}$ \\
\hline Entrevistada 4 & $\begin{array}{l}\text { Agora eu tenho contato da empresa de contabilidade tenho ainda projeto } 2 \text { projeto e ainda } \\
\text { estou secretário-geral do partido ou seja eu acordo cedo e durmo sufocada é muita coisa a } \\
\text { única coisa que eu não deixo não final de semana que é sagrada. }\end{array}$ \\
\hline
\end{tabular}

Fonte: Dados da Pesquisa (2018).

Isso reflete bem o empoderamento feminino, a partir das lutas e conquistas citadas por Brasil (2018) e a sua resiliência no desempenho das atividades pessoais e corporativas citadas por Kumruian (2018) e Campos (2018), fatores estes percebidos nas verbalizações principalmente das entrevistadas 2, no destaque para realização: "mas compensa, eu não trocaria minha vida de casada com filho e trabalhando fora" e o planejamento mencionado pela 3: "[...]minha rotina quinta e sexta faço mais no planejamento e segunda terça e quarta faço acompanhamento em lote[...]”.

Quadro 5: Categoria "Desempenho"

\begin{tabular}{|l|l|l|}
\hline Participantes & \multicolumn{1}{|c|}{ Relação com a área da logística } & \multicolumn{1}{c|}{ Conhecimento a área } \\
\hline Entrevistada 1 & $\begin{array}{l}\text { Logística interna na parte de } \\
\text { processamento de pedidos, onde a gente se } \\
\text { disponibiliza a programação a modelação vai } \\
\text { prensar e isso envolve a distribuição de } \\
\text { matérias dentre setores a setores, e externa a } \\
\text { gente só trabalha com um cliente, mas o } \\
\text { cliente mesmo que vem pegar o material, mas } \\
\text { é a parte de processos e planejamento.... } \\
\text { intralogistica }\end{array}$ & $\begin{array}{l}\text { Bom estou fazendo a pós agora de } \\
\text { logística, estou terminando agora em } \\
\text { janeiro e assim meu conhecimento eu não } \\
\text { digo sei tudo sabe, porque tudo ninguém } \\
\text { sabe, mas assim eu sou uma pessoa muito } \\
\text { interessada pela área e procuro tentar me } \\
\text { atualizando, é relacionado não à logística } \\
\text { completa mas eu gosto muito da parte de } \\
\text { interna que aqui o prático de processo e } \\
\text { também é eu estou mais me vendo mais a } \\
\text { área de exportação que meu TCC vai ter que } \\
\text { fazer isso estou me aprofundando mais } \\
\text { sobre essa questão de importação e } \\
\text { exportação mas assim no geral, eu domino } \\
\text { essa parte logística porque o você se } \\
\text { interessa você sabe né. }\end{array}$ \\
\hline Entrevistada 2 2 & $\begin{array}{l}\text { Bomtão eu acho que assim, eu sou formada } \\
\text { em engenharia eu tenho uma pós- }\end{array}$ \\
\hline
\end{tabular}




\begin{tabular}{|c|c|c|}
\hline & $\begin{array}{l}\text { trabalhando programando material, aí } \\
\text { assim eu tenho vários fornecedores que não } \\
\text { cumprem entrega a gente tem por exemplo uma } \\
\text { carreta por mês saindo de São Paulo para cá } \\
\text { com } 24 \text { toneladas de peças mas eu tenho um } \\
\text { fornecedor que não entrega aqui que a gente } \\
\text { faz a gente trabalha o modal aéreo e informa } \\
\text { que não você não entregou você tá atrasado. } \\
\text { Então você vai ter que mandar esse material } \\
\text { pra mime por conta sua, a gente também } \\
\text { trabalha com material importado da China aí } \\
\text { esse daí também sou a programadora dele, eu } \\
\text { tenho que ter } 3 \text { meses no estoque de peças na } \\
\text { fábrica desse material importado do material } \\
\text { Nacional eu só tenho autorização de um mês } \\
\text { mas do importado ele passa também no navio } \\
\text { mais uns } 15 \text { dias para liberar mais } 5 \text { dias } \\
\text { viajando então aí qualquer problema que der } \\
\text { vai me afetar diretamente por isso que eu tenho } \\
\text { que ter esses três meses em estoque. }\end{array}$ & $\begin{array}{l}\text { graduação em logística, que eu terminei } \\
\text { essa pós em } 2012 \text { depois disso eu nunca } \\
\text { mais fui fazer outra que eu deveria estar } \\
\text { fazendo que é bom a gente sempre está se } \\
\text { especializando cada vez mais, mas eu não } \\
\text { sei, eu acho que não tenho tempo e me } \\
\text { especializar mais do que eu já me } \\
\text { especializei, porque quando eu terminei o } \\
\text { MBA eu nem tinha meu filho, então agora } \\
\text { não tenho nem coragem de fazer outra } \\
\text { especialização me aprofundar mais no } \\
\text { assunto ao não ser depois que meu filho } \\
\text { estiver maior por que agora ele precisa } \\
\text { muito de mim. }\end{array}$ \\
\hline Entrevistada 3 & $\begin{array}{l}\text { Mais na área de planejamento. } \\
\text { Acompanhamento em lotes, compras de } \\
\text { suprimentos. }\end{array}$ & $\begin{array}{l}\text { Meu nível de conhecimento seu deu com } \\
\text { minha trajetória, com a pratica } \\
\text { aprendendo foi apanhando muito, foi } \\
\text { errando, foi acertando, foi durante o curso } \\
\text { e gostava de exatas. }\end{array}$ \\
\hline Entrevistada 4 & $\begin{array}{l}16 \text { anos que eu trabalhei eu amava o que eu } \\
\text { fazia, eu amo na verdade, hoje você tanto que } \\
\text { hoje eu dou treinamento para logística ainda } \\
\text { tenho tantos contatos muitas } \\
\text { transportadoras aqui gestores e } \\
\text { transportadora me procuram quando tem } \\
\text { dúvida por exemplo a Cubagem de uma carreta } \\
\text { nem todo mundo consegue acompanhar com } \\
\text { base altura Largura comprimento e eu tenho } \\
\text { uma ótica que eu consigo, nesse } 16 \text { anos que eu } \\
\text { trabalhei, fiquei muito focada na operação eu } \\
\text { consigo saber quantos volumes consegue } \\
\text { transportar uma carga então essa minha } \\
\text { facilidade os gestores os proprietários de } \\
\text { transportadora de redes pacho que a divisão da } \\
\text { carga eles me procuram para poder tirar } \\
\text { dúvidas então eu mantenho escritório } \\
\text { contabilidade mas continuo na logística tem } \\
\text { sempre aquela conversa. }\end{array}$ & $\begin{array}{l}\text { Eu falei que você está se adaptando } \\
\text { conhecimento, recentemente eu dei um } \\
\text { treinamento que eu sou palestrante } \\
\text { também eu dei um treinamento sobre as } \\
\text { abordagens de logística qual a conduta, } \\
\text { dizendo atendimento ao cliente, como vai } \\
\text { falar para o que atrasou, então esse meu ato } \\
\text { de palestra e estudar porque você não pode } \\
\text { palestrar sem ter conhecimento na área. }\end{array}$ \\
\hline
\end{tabular}

Fonte: Dados da Pesquisa (2018).

E ainda que não se tenha demérito o cansaço advindo das atribuições, se observa que a disciplina contribui para o desempenho das atividades inerentes ao planejamento logístico de cada profissional. As entrevistadas atuam principalmente na intralogística (03 delas), desempenhando atividades de programação, compras e suprimentos, e todas tem formação profissional na área. Fato esse que pode ser favorecido pelos dados apresentados por Gauchazh (2018), ao destacar a valorização da profissão ao longo dos anos e para o futuro, em função da ineficiência logística que existe no país. 
Quadro 6: Categoria "Perfil Profissional"

\begin{tabular}{|c|c|c|c|}
\hline Participantes & $\begin{array}{l}\text { Características que se } \\
\text { destacam na logística }\end{array}$ & Dificuldades na atuação & $\begin{array}{c}\text { Essencial no âmbito do } \\
\text { sucesso }\end{array}$ \\
\hline Entrevistada 1 & $\begin{array}{l}\text { A competência é uma } \\
\text { característica que você tem } \\
\text { que ter todo ramo que você se } \\
\text { dedique, tem que ter } \\
\text { competência se você tiver } \\
\text { competência você vai longe, e } \\
\text { você é bom em tudo aquilo que } \\
\text { você vai fazer a competência a } \\
\text { determinação também não } \\
\text { fraquejar diante das } \\
\text { dificuldades, eu digo por mim } \\
\text { você não desistir no primeiro } \\
\text { não, eu acho que isso é uma } \\
\text { característica relevante. }\end{array}$ & $\begin{array}{l}\text { Além do preconceito de não } \\
\text { acreditar na mulher, eu acho } \\
\text { que é isso mesmo mas a } \\
\text { questão feminina, isso que } \\
\text { que faz com que as mulheres } \\
\text { não se interessam por esse } \\
\text { ramo por pensar que não } \\
\text { vão ser vistas não vão ser } \\
\text { acreditadas acho que mais } \\
\text { por isso porque assim } \\
\text { depende muito da pessoa que } \\
\text { seja interessante para esse } \\
\text { ramo porque se você não } \\
\text { acreditar em si, e não quiser } \\
\text { provar para os outros que } \\
\text { você é capaz nem invente é } \\
\text { mais por isso. }\end{array}$ & $\begin{array}{l}\text { Determinação como eu já } \\
\text { falei, perseguir aqueles que } \\
\text { você tem em mente que você } \\
\text { quer chegar no patamar de uma } \\
\text { empresa, você vai ter que, não } \\
\text { necessariamente começar nele } \\
\text { mas, você tem que perseverar } \\
\text { naquilo que você quer e não } \\
\text { desistir na primeira } \\
\text { dificuldade, acho que em tudo } \\
\text { na vida, não só no ramos da } \\
\text { logística mas como a gente tá } \\
\text { mesmo tema, é você ter } \\
\text { perseverança e logico você ter } \\
\text { um conhecimento porque seu } \\
\text { conhecimento você não chega } \\
\text { a lugar nenhum e para você ter } \\
\text { o conhecimento não chega a } \\
\text { lugar nenhum, e para você ter o } \\
\text { conhecimento você tem que } \\
\text { estudar está atualizado } \\
\text { relacionada à área isso daí é } \\
\text { fundamental. }\end{array}$ \\
\hline Entre & $\begin{array}{l}\text { Eu acho que a mulher ela é } \\
\text { mais perfeccionista mais } \\
\text { detalhista, do que o homem } \\
\text { mais paciente explica melhor, } \\
\text { tem mais paciência para lidar } \\
\text { com as pessoas o homem às } \\
\text { vezes estoura muito rápido e a } \\
\text { mulher sempre tem assim uma } \\
\text { diferenciação do homem que } \\
\text { ela vai ter mais paciência, vai } \\
\text { saber se desdobrar mais assim } \\
\text { para conseguir o que ela quer. }\end{array}$ & $\begin{array}{l}\text { Não, quando você colocou } \\
\text { feminina nenhuma. }\end{array}$ & $\begin{array}{l}\text { Eu acho que ela tem que ser } \\
\text { persistente, não pode ter } \\
\text { vergonha, não pode ficar } \\
\text { calada se não concorda nem } \\
\text { que seja com o chefe tem que } \\
\text { falar, não é só necessariamente } \\
\text { na logística, pois você não vai } \\
\text { conseguir em nenhuma outra } \\
\text { profissão. Porque se você for } \\
\text { só daquela que vai baixar a } \\
\text { cabeça mas falar que está } \\
\text { errado tem que ter opinião, } \\
\text { falar seu ponto de vista para } \\
\text { melhorar em qualquer fator se } \\
\text { concorda ou se não concorda. }\end{array}$ \\
\hline Entre & $\begin{array}{l}\text { Eu vejo que a mulher ela } \\
\text { tem mais atitude em relação } \\
\text { a resolver os demais } \\
\text { problemas, tipo lá na xxx, são } \\
\text { todas mulheres, eu perguntei o } \\
\text { por que e disse por que elas } \\
\text { resolvem. }\end{array}$ & $\begin{array}{l}\text { A dificuldade que eu vejo não } \\
\text { só na área de logística, mas } \\
\text { assim abrangendo todo o } \\
\text { mercado de trabalho da } \\
\text { credibilidade a mulher } \\
\text { independendo de qualquer } \\
\text { área. }\end{array}$ & $\begin{array}{l}\text { É ter interesse de você } \\
\text { aprender a disposição de } \\
\text { você saber fazer, aquilo bem } \\
\text { feito entregar proposta e } \\
\text { resultados na hora certa no } \\
\text { momento certo. }\end{array}$ \\
\hline Entrevistada 4 & $\begin{array}{l}\text { A mulher ela é muito } \\
\text { caprichosa, a mulher é muito } \\
\text { compromissada, deu um } \\
\text { problema na mão da mulher } \\
\text { impossível ela não resolver, o } \\
\text { homem ainda tem uma certa } \\
\text { dificuldade de acompanhar não } \\
\text { generalizando e mulher tem a } \\
\text { visão de } 360 \text { graus ela consegui } \\
\text { identificar situações ainda } \\
\text { deixa bonito. }\end{array}$ & $\begin{array}{l}\text { Dificuldade aquela que eu } \\
\text { vou voltar a falar sobre carga } \\
\text { e descarga a mulher na } \\
\text { logística ela pode entrar em } \\
\text { qualquer área, se ela } \\
\text { pretender ser ajudante carga e } \\
\text { descarga Tudo bem mas a } \\
\text { anatomia dela não consegue a } \\
\text { isso, a mulher não pode pegar } \\
\text { peso, a musculatura do } \\
\text { homem aceita, a mulher não, } \\
\text { a dificuldade é essa, não é } \\
\text { fechado. }\end{array}$ & $\begin{array}{l}\text { Conhecimento se preparar } \\
\text { sempre, ser curiosa, aceitar } \\
\text { oportunidade o meu caso } \\
\text { comecei como auxiliar de caixa } \\
\text { e está lá sempre para o que } \\
\text { precisar. }\end{array}$ \\
\hline
\end{tabular}

Fonte: Dados da Pesquisa (2018). 
Quanto ao perfil profissional, se percebe tanto na literatura, quanto na atuação das profissionais, as características citadas por Campos (2018) e Rodrigues (2017). É um vasto campo de atuação para as mulheres dadas as características destacadas nas palavras incidentes nas falas da entrevistadas e em consonância com a literatura "competência, determinação, perseverança, conhecimento, perfeccionista, detalhista, com atitude, disposição, compromisso e curiosidade"

Quadro 7: Categoria "Carreira em Logística"

\begin{tabular}{|c|c|c|}
\hline Participantes & Como você se ver na profissão & Reconhecimento \\
\hline Entrevistada 1 & $\begin{array}{l}\text { Me vejo hoje... eu não estou totalmente } \\
\text { realizada porque eu ainda quero muito } \\
\text { mais, mas o que eu vivo hoje aqui na } \\
\text { fábrica é um pequeno passo que eu tô } \\
\text { dando para um futuro que eu vejo assim } \\
\text { que se eu estou trilhando e eu estou no } \\
\text { caminho certo eu tô na área da logística, eu } \\
\text { tô fazendo pós para logística eu estou } \\
\text { atuando numa pequena parte da grande } \\
\text { Gama que é hoje no Brasil, mas eu me } \\
\text { vejo estou trilhando o caminho certo. }\end{array}$ & $\begin{array}{l}\text { Sim, aqui como eu já te disse eu comecei } \\
\text { trabalhando para área do RH e eles precisavam } \\
\text { de uma pessoa com experiência e eu estava } \\
\text { acabando de sair da faculdade me encaixo nesse } \\
\text { perfil } e \text { hoje assim é a oportunidade que me } \\
\text { deram aqui relacionada ao PCP uma coisa } \\
\text { que eu também nunca tinha feito, foi enorme } \\
\text { assim lá uma gama de aprendizado coisa que } \\
\text { eu nunca tinha feito que hoje eu domino } \\
\text { completamente. }\end{array}$ \\
\hline Entrevistada 2 & $\begin{array}{l}\text { Eu acho que estou no âmbito bom, eu } \\
\text { gosto porque graças a Deus a gente nunca } \\
\text { teve problema. }\end{array}$ & $\begin{array}{l}\text { Já sim por exemplo de aumento de salário a } \\
\text { gente sabe que é difícil né mas sempre ele } \\
\text { merece ele fica em São Paulo quando ele vem } \\
\text { ele conversa até por e-mail a gente manda uma } \\
\text { planilha ele agradece às vezes ficado ótimo ele } \\
\text { disse não tivéssemos a melhore nesse ponto mas } \\
\text { ele sempre agradece. }\end{array}$ \\
\hline Entrevistada 3 & $\begin{array}{l}\text { Eu sou muito satisfeita, Eu amo o que } \\
\text { eu faço. }\end{array}$ & $\begin{array}{l}\text { Já sim, em relação os aumentos de salários } \\
\text { que tive eu nuca cheguei a pedir. }\end{array}$ \\
\hline Entrevistada 4 & $\begin{array}{l}\text { Sou muito vaidosa, eu sou uma } \\
\text { excelente profissional, tanto no âmbito } \\
\text { de logística, pois muitos convites ainda } \\
\text { chegam. }\end{array}$ & $\begin{array}{l}\text { Já sim como eu era caixa, depois fui } \\
\text { monitora e assim fui crescendo. }\end{array}$ \\
\hline
\end{tabular}

Fonte: Dados da Pesquisa (2018).

Por fim, observa-se que as profissionais entrevistadas estão na direção evolutiva no contexto de empoderamento feminino, demonstrando que estão não apenas aptas a atuarem no ramo da logística, mas principalmente, tem competência para tal. E na contramão dos preconceitos, ainda vigentes, se destacam em suas atuações, podendo perceber, inclusive, reconhecimentos advindos de seu trabalho e dispostas a galgar uma carreira de sucesso. 


\section{Considerações Finais}

Com o objetivo de compreender os desafios enfrentados pela mulher frente a atual conjuntura e exigências no tocante à inserção e manutenção da profissão, se pode considerar, a partir do estudo realizado que o cenário vigente é de mudanças aceleradas, principalmente no tocante à mudanças de profissões e acesso à tecnologia avançada, mas que a mulher, frente à diversas lutas que vem travando ao longo dos anos, vem conseguindo se posicionar e se destacar na sociedade e no mercado de trabalho. Suas conquistas perpassam os direitos merecidos e adentram o universo da competência em igualdade de gênero no desempenho de suas atribuições.

No âmbito da logística, profissão que tem destaque para atividades desde operacionais até estratégicas, a mulher ganhou espaço e vem se consolidando a partir da efetividade dos planejamentos e manejo com as informações e lideranças, quebrando o paradigma de que esta é uma atividade meramente masculina.

O contexto apresentado ainda traz à tona alguns desafios, com destaque especialmente às jornadas exaustivas para administrar a rotina pessoal, muitas vezes com marido e filhos, perpassando a aceitação pelos pares e até o desempenho corporativo, que as entrevistadas no estudo e observadas na literatura exposta não tem deixado à mercê.

A pesquisa discutiu brevemente aspectos relativos à evolução da mulher no mercado de trabalho, empoderando-a, à partir das lutas por meio de movimentos sociais, bem como apontou os destaques no quesito gestão logística. E a partir dos resultados alcançados percebe-se a importância de se realizar um levantamento mais detalhado que contemple número de mulheres inseridas em atividades logísticas na região do cariri por ramo de negócio, fazendo um comparativo, por meio de dados estatísticos e correlacionando o desempenho antes e depois de sua atuação, bem como o nível de remuneração percebido, observando assim o cenário local e global.

\section{Referências}

BALLOU, Ronald H. Gestão de pessoas: Gerenciamento da cadeia de suprimentos/logística empresarial. 5. Ed. São Paulo: Laser House, 2004. 26p. 
BALLOU, Ronald H. Gerenciamento da cadeia de suprimentos/logística empresarial [recurso eletrônico] / tradução Raul Rubenich. - 5. ed. - Dados eletrônicos. - Porto Alegre: Bookman, 2007.

BRASIL. Empoderamento feminino reflete luta das mulheres por igualdade social. Disponível em: <http://www.brasil.gov.br/noticias/cidadania-e-inclusao/2018/vctemvoz /empoderamento-feminino-reflete-luta-das-mulheres-por-igualdade-social> Acessado em: 25 nov. 2018.

CAMPOS, Rafaela. Mais mulheres na TI e na logística. Disponível em: <https://portogente. com.br/noticias/opiniao/100244-mais-mulheres-na-ti-e-na-logistica $>$ Acessado em: 20 out. 2018 .

DUARTE, Vânia, NASCIMENTO, Maria. Pesquisas: Exploratória, Descritiva e Explicativa. 2012. Disponível em: <https://monografias.brasilescola.uol.com.br/regras-abnt/pesquisasexploratoria-descritiva-explicativa.htm>. Acesso em: 21 mai.2018.

GAUCHAZ. Conheça 10 profissões do futuro e cursos de graduação ligados a elas. Disponível em: <https://gauchazh.clicrbs.com.br/educacao-e-emprego/noticia/2018/11/conheca-10profissoes-do-futuro-e-cursos-de-graduacao-ligados-a-elas-cjo4xeos50bji01rxtuxoct6q.html> Acessado em: 08 nov. 2018.

LIMA JUNIOR, Orlando Fontes. São várias as tendências tecnológicas na intralogística. 2017. Revista Logweb. Ed. 184. Out. 2017.

MARQUES, José Roberto. Entendendo os conceitos de Entrevista Estruturada e Não Estruturada. 2018. Disponível em:<https://www.ibccoaching.com.br/portal/mercadotrabalho/entendendo-os-conceitos-de-entrevista-estruturada-e-nao-estruturada/ $>$. Acesso em: 21 maio 2018.

MEDONÇA, Jorge. A Evolução da Mulher no Mercado de Trabalho. 2017. Disponível em: $<$ https://jorgeluizmendonca.jusbrasil.com.br/artigos/473171435/a-evolucao-da-mulher-nomercado-de-trabalho?ref=topic_feed>. Acesso em: 10 ago. 2018.

MUNDO LOGÍSTICA. Mulheres constroem caminho para ganhar espaço na Logística. 2018. Disponível em: <https://www.revistamundologistica.com.br/noticias/mulheresconstroem-caminho-para-ganhar-espaco-na-logistica>. Acesso em: 15 maio 2018.

PORTAL EDUCAÇÃO. Logística empresarial e a Atividades primárias e de apoio. Disponível em: <https://www.portaleducacao.com.br/conteudo/artigos/conteudo/logistica /31365> Acessado em: 20 out. 2018.

PROBST, Elisiana Renata. A evolução da mulher no Mercado de trabalho. 2015. Disponível em:〈https://www.rhportal.com.br/artigos-rh/a-evoluo-da-mulher-no-mercado-de-trabalho/>. Acesso em: 10 maio 2018.

POZO, Hamilton. Administração de recursos materiais e patrimoniais: Uma abordagem logística. 7.ed. São Paulo: Atlas, 2015. 
REVISTA MUNDO LOGÍSTICA. Mulheres constroem caminho para ganhar espaço na logística. Disponível em: < http://www.revistamundologistica.com.br/noticias/mulheresconstroem-caminho-para-ganhar-espaco-na-logistica> Acessado em: 10 nov. 2018.

RODRIGUES, Arildo. Lugar de Mulher é na manutenção. 2017. Disponível em: <http://www.ietec.com.br/imprensa/lugar-de-mulher-e-na-manutencao/>. Acesso em: 21 ago. 2018.

SALES, André. Muita experiência é pouco em logística. 2007. Revista Tecnologística. Fevereiro, 2007. p. 48 à 56.

SILVA, Andressa Hennig; FOSSÁ, Maria Ivete Trevisan. Análise de Conteúdo: Exemplo de Aplicação da Técnica para Análise de Dados Qualitativos. IV Encontro de Ensino e Pesquisa em Administração e Contabilidade. Brasilia/DF, 2013.

YIN, Robert K. Estudo de Caso: Planejamento e métodos. Trad. Daniel Grassi. 2 ed. Porto Alegre: Bookman, 2001.

Como citar este artigo (Formato ABNT):

BORGES, Maria Taina Araujo Silva; OLIVEIRA, Alyne Leite de. A Mulher e sua Atuação no âmbito da Logística: Um estudo de casos múltiplos na Região do Cariri. Id on Line Rev.Mult. Psic., 2019, vol.13, n.43, p. 490-505. ISSN: 1981-1179.

Recebido: 05/12/2018;

Aceito: 07/12/2018 